\title{
Refugees, Health Management, and Cultural Influence
}

\author{
Nada Alfeir ${ }^{1}$ \\ ${ }^{1}$ ABD, Rhetoric, Theory, and Culture program, Michigan Technological University, Houghton, MI, USA \\ Correspondence: Nada Alfeir, ABD, Rhetoric, Theory, and Culture program, Michigan Technological University, \\ Houghton, MI, USA. E-mail: nalfeir@mtu.edu
}

Received: March 21, $2020 \quad$ Accepted: May 6, $2020 \quad$ Online Published: May 17, 2020
$\begin{array}{ll}\text { doi:10.5539/gjhs.v12n7p142 } & \text { URL: https://doi.org/10.5539/gjhs.v12n7p142 }\end{array}$

\begin{abstract}
Although the magnitude and increase in refugee's situation are well recognized, information related to their health management remains limited. Mainly, the influence of culture in refugee health management is lacking. This study, therefore, provides a review of fifty previous researches and explores the barriers which impede the quality care of the refugee population. It discusses the health issues through a case study of the International Institute of Akron in Akron, Ohio. Results show that health management for refugees is primarily affected due to language differences, which impacts patient-physician communication, followed by health beliefs, religious beliefs, and patients' stereotyping and discrimination.
\end{abstract}

Keywords: Refugee health, care quality, culture influence, patient-physician communication

\section{Introduction}

The refugee population and their issues have grown substantially over the last few decades (Spaaij et al., 2019; Neumann et al., 2014). Due to current civil wars such as in Sudan and Yemen, the refugee crisis continues to escalate. United Nations High Commissioner for Refugees (UNHCR) has reported that approximately 56 million people were displaced. In Syria alone, approximately 6.7 million people were internally displaced, while 3.5 million were seeking asylum in other countries (UNHCR, 2018). Mangrio and Forss (2017) indicated that understanding of the refugee health experience is critical for improving their health outcomes. It is widely viewed that maintaining adequate health conditions for the refugee is integral for their effective integration in society and the labour market (Campbell et al., 2014).

Abubakar and Zumla (2018) showed that population movements inevitably cause adverse effects on health care delivery, increasing the responsibility of national governments and international bodies. Also, the United Nations' (UN) development of the Global Compact for Safe, Orderly and Regular Migration and the Global Compact on Refugees have increased the commitment to ensure high-quality care and curative health need of the refugee population. However, a decline is observed in the refugee health status concerning their settlement in the host country (Mangrio \& Forss, 2017). This is because of the various risk factors which prevail in the migration process alone, which make an individual vulnerable to ill health (Bempong et al., 2019). Some of the factors that can challenge patient-physician communication include insufficient patient health literacy, language differences, and cultural differences (Schyve, 2007). For instance, the attitudes, beliefs, and religious values of Saudi people are unique, and characterized by different customs, traditions, and Islamic law (Almutairi \& McCarthy, 2012).

For the International Institute of Akron, the identified barriers in the study are required to be adequately managed for fostering patient-physician communication using the patient-centered approach (King \& Hoppe, 2013). In a patient-centered approach, the physician elicits and understands the perspectives of the patient, including ideas, values, concerns, feelings, etc (Hashim, 2017). Moreover, taking a patient-centered approach requires physicians to understand the unique culture, psychosocial contexts and shared understanding of the problem. It also helps in communication or suggesting treatment options that align with the beliefs and values of the patient.

Moreover, refugees are often cared for by physicians with different cultural backgrounds than their own. Thus, communication between the refugee patients and physicians can be strained. Since refugee camps often accommodate people from different regions and backgrounds, health decline may be attributed to cultural diversity. This cultural diversity affects effective patient-physician communication causing detrimental impact on the quality and safe delivery of healthcare needs (Schyve, 2007), such as poor adherence to medications, patient dissatisfaction, and adverse health outcomes (Wynia \& Osborn, 2010). The healthcare needs of refugee patients are 
substantial, considering their suboptimal living conditions, lack of vaccination, and crowded living places (Van Loenen et al., 2017; Kira, Amer, \& Wrobel, 2014). Also, the diverse culture can influence the view of refugees for sharing or utilizing health resources (Napier et al., 2015). Therefore, the present study aims to determine the effect of cultural factors on the health management of refugees.

Drawing on UNHCR commissioned report; the cultural factors were comprehensively investigated through a case study at the International Institute of Akron (IIA) in Akron, Ohio. IIA is a non-profit agency that assists the foreign-born as they transition to live in the United States. The health-related services offered by the IIA include mental and physical health care, solving medical issues that bar an individual from independence, helping refugees schedule and attend medical and mental health appointments and helping them solve problems related to ethnic values, cultural differences, and different experiences and perceptions (International Institute of Akron, 2014). Frost, Markham, and Springer (2018) further showed that approximately 70,000 refugees were settled in the United States in the year 2015.

Many refugees in Akron have serious health problems such as obesity, overweight, and diabetes. According to Kumar et al. (2014), the refugees' resettlement health needs, in Ohio, include the poor nutritional status of the individuals, poor self-rating of the health, and mental health disorder prevalence, including a disproportionate suicide rate. United States Department of Health and Human Service's Office of Refugee Resettlement in the years 2009 to 2012 showed that the Bhutanese refugees' suicide rate was 20.3 per 10000 individuals, which was twice the rate of US general population (Hagaman et al., 2016; Ellis et al., 2015). Ohio Department of Mental Health reported that $30 \%$ of refugees suffered from anxiety, and $26 \%$ from depression (Schultze, 2018).

These statistics show that the International Institute of Akron has serious health issues that require immediate attention. Community health workers were in a good position to help refugees tackle health issues through behavior contracts and goal setting (Purnell, 2013). However, cultural factors such as religion, beliefs, previous experience, attitudes, and values influence the health behaviours of the refugees (Purnell, 2013). To better address health issues at Akron, it was important to understand the cultural factors that affect health behaviours and decision-making.

Health promotion is defined as the process, allowing individuals to improve their control on the health determinants for better health (Spaaij et al., 2019). Understanding the cultural context was crucial when studying beliefs concerning health. Goodridge (2002) writes that health promotion follows a cultural concept that frames how individuals shape and perceive their world and experiences. It is because the health understanding and interpretation among individuals vary based on their culture. Choudhry et al. (2016) reported that illness perception generally explains the health seeking behaviour of the individuals. Also, Beardsmore \& McSherry (2017) explained culture as a complex phenomenon integrating various factors that affect the delivery of compassionate care. These factors include professional practice, workforce, support, and service delivery.

Various studies have argued that culture helps define how health care providers and patients view health and illness (Purnell, 2013; Clarkson Freeman et al., 2013), while some highlighted that culture influences the health-seeking behaviours of individuals. For instance, African-Americans have strong family ties, and individuals were usually expected to seek healthcare from family members before looking for healthcare professionals (Purnell, 2013). Similarly, Clarkson Freeman et al. (2013) on Somalia refugees showed that cultural misconceptions and discordant beliefs concerning health were the main barriers in accessing healthcare (Kumar \& Preetha, 2012).

Culture also plays a key role in how a diagnosis is accepted, including when, how, and who should be told. It also affects the willingness of the patient to discuss their symptoms with the healthcare provider (Goodridge, 2002). The perceptions professed by patients are based on views of death, youth, and aging that affect health treatment methods. How accessible the health system is and the acceptance of health promotion measures such as vaccines, screening tests, birth control, are all dependent on the patient's cultural views (Corby, 2010). Moreover, culture affects health through the mode of communication used, wherein some cultures making or avoiding eye contact was viewed as being polite or rude.

Cultural difference of patients also includes the diverse religions or faiths to which the patients ascribe, and can pose a major barrier to treatment (Fowler, 2012). For example, some faiths do not accept the use of modern medicine, which can be a major impediment to the treatment of refugees (Corby, 2010). Further, some religions advocate for health issues to be addressed by family members rather than professional practitioners. For these reasons, working with people from different cultural and spiritual backgrounds calls for understanding and tolerating vagueness and uncertainty. Groen et al. (2018) stated that healthcare staff are open-minded and can greatly help understand the refugee patients' conditions and health changes, which one might have undergone, and alleviate and navigate cultural tensions and uncertainty. 
Gerteis, Levitan, Daley, \& Delbanco's (1993) book “Through the Patient's Eyes” offers a look at the importance of offering emotional support to patients. It discusses the value of offering emotional assistance to patients from different cultural backgrounds by acknowledging the patient's feelings, encouragement of expressing beliefs openly, expressing positive affect, offering tangible support, and a sense of belonging. Fowler (2012) also emphasized that healthcare providers must treat patients from different spiritual beliefs and cultural backgrounds with respect. In summary, effective patient-physician communication is essential to realize better health outcomes.

\section{Methodology}

A qualitative research design is adopted to analyze the cultural factors which impact the patient-physician relationship. For this, the search strategy included studies and literature related to the research scope concerning cultural factors among refugees. The study has set the search limit from January $1^{\text {st }} 2008$ to December $31^{\text {st }} 2018$.

Publications in English language were preferred in the inclusion criteria. The study has included all types of articles including reviews in order to analyze the cultural factors impacting the patient-physician relationship. Online research databases were used for this literature review, including PsycInfo, PubMed, Google Scholar, and Scopus. Based on the reviewed literature, the study makes recommendations for the International Institute of Akron as well as institutions working with older adult refugees. The final sample of the study included 50 studies, which have been examined for identifying the cultural factors impacting the patient-physician relationship.

Initially, 475 abstracts were explored and retrieved, out of which 225 full-text articles were extracted for further selection. Based on the inclusion criteria, a total of 50 articles were selected undertaking language differences, health beliefs, religious beliefs, discrimination and stereotypes, acculturation, social factors in communication, traumatic experience, communication and aging, generation cross-culture, and new culture adaptation. These articles were selected based on quality checks. Few of the articles were reported to have high risk of bias. A content analysis was preferably used to analyze the themes mentioned above.

\section{Findings}

Culture can be defined as a meaning-making system in which ethnicity, behaviour, and values are significant (Hughes, Van Heugten, \& Keeling, 2015). Other factors, such as religion, family roles, and behavioral engagements can also be used to define the culture of a group (Corby, 2010). Out of 50 studies, two of the studies have shown that culture is closely related to communication (Von et al., 2008; Almutairi, 2015). It was argued that patient-physician communication is also linked with different outcomes such as adherence, patient satisfaction, health outcomes, and cultural diversity can complicate patient-physician communication (von, Silverman, Cushing, Quilligan, Salisbury \& Wiskin, 2008). Piacentini et al. (2019) have indicated that different refugee groups possess different language capacities, which adversely affects health discussions. Intercultural patient-physician communication is a potential source of misunderstanding, which in turn can reduce the quality of healthcare.

\subsection{Language Differences}

A total of three studies have found that language influences patient-physician communication (Degni, Suominen, Essen \& Vehvilainen-Julkunen, 2012; Diamond LC, Tuot \& Karliner, 2012). One of the studies have identified that differences in language cause increased stress and pain among patients as they may use culturally specific terms, metaphors or expression, which might be difficult for practitioners to navigate (Meuter et al., 2015). This further complicates when clinicians lack interpreters, and; therefore, has to rely on experienced, bilingual, and non-medical staff which may compromise the quality of care.

The main objective for physicians during consultations is to understand patient and language differences that can affect the interaction. One of the studies have indicated that different strategies explain the diagnosis to the patient and the ability to use attributes such as an interpreter, pictures, etc., when language differences arise (Ge, Burke, Somkin, \& Pasick, 2009). Another study has indicated that skills are essential for patient-physician communication, including listening, avoiding jargon, and explaining medical information (Song, Hamilton, \& Moore, 2011). According to Paternotte et al. (2015), repeating the exact words of the patient or paraphrasing can encourage patients to explain their problems.

Blignault et al.'s (2008) study found that language barriers hinder the patient's ability to express emotions and communicate symptoms, thereby impacting the type of medical help needed. In contrast, Sandhu et al (2013) have noted that the language ability of the patients is considered a significant barrier for clinicians (Sandhu et al., 2013). A study by Cross and Bloomer (2010) found that clinicians experienced difficulties describing symptoms in simple terms when there is a language difference, affecting adherence to the recommended treatment. Sandhu et al. (2013) also found out that language fluency was a key factor that led clinicians to fail to judge the severity of symptoms 
adequately, understand the problems of the patient, and make a correct diagnosis. Wolz et al.'s study (2015) stated that communication barriers impact patients' diagnoses, investigations, and management. For example, when an interpreter is present, the healthcare expert is likely to formulate his or her opinion based on the interpreter rather than the specific words (p. 249).

Garrett et al. (2008); on the non-English speaking patients, found that limited English proficiency among patients makes them feel powerless, causing a detrimental impact on their confidence, anxiety, sense of dependency, and fear. The study has also found that immigrant patients were unlikely to report their problems to the healthcare system. However, Garrett et al. (2008) suggested that these cases were preventable using compassion, family involvement, and appropriate language facilitation.

Zhao (2010) identified differences in the information-seeking behaviour of individuals from different backgrounds. Hispanics born in the United States were shown to be more likely to seek cancer information as compared to foreign-born Hispanics. In addition, Neo's (2011) also found language to affect medical communication in terms of the communicative behaviour of physicians and the willingness of patients to share critical information. Neo (2011) found that the communication style of physicians influences initial discussions and subsequent appointments. However, it was not clear which of the communication styles have impact on patient health beliefs and adherence. According to Santosh, Fay, Gayatri \& Carmen (2014), non-verbal behaviours are important for effective communication. According to Thome et al. (2013), there are some communication errors associated with non-verbal behaviour, including systematic misunderstandings, occasional misses, and repeated mistakes. The willingness of physicians to address such errors can enhance communication and consequently improve treatment outcomes.

\subsection{Health Beliefs}

Molfenter \& Brown (2014) have found that the values and beliefs of both the patient and physician affect patient-physician communication. Molfenter \& Brown (2014) further argued that diverse values and beliefs can affect the patient-physician relationship leading to distrust of the therapies prescribed, fear of the healthcare system, and competing therapies. Patient-physician communication is a key determinant of adherence to treatment recommendations. The health beliefs of patients are important factors that lead to healthy behaviours (Street, et al., 2009). Thus, if the beliefs of the patient and physicians differ, communication may break due to the development of disagreements.

Two of the studies have shown that differences in health beliefs influenced patient-physician communication (Nguyen, Barg, Armstrong, Holmes \& Hornik, 2008; O’Dougherty \& Mehta, 2012). A study by Nguyen, Barg, Armstrong, Holmes, \& Hornik (2008) among Vietnamese patients found that there was a general belief that speaking about an illness would stimulate its development. Such a belief was not understood by physicians, and thus, discussion of preventive strategies for certain illnesses caused distress and fear in Vietnamese patients. Moreover, the patients also failed to discuss apparent symptoms because of the fear that they will cause the illness to progress faster.

Another study by Shannon, O’Dougherty \& Mehta (2012) in the U.S. found that some Asian, South American, and African refugees did not perceive emotional distress as a health problem, and thus, did not share this with physicians. Rocque \& Leanza (2015) highlight that the dominance of the biomedical culture impacts the patient's treatment as healthcare providers are likely to exclude the psychosocial aspect with a major focus on the consultation provided. This makes the patient feel uncontrolled and helpless, eventually impacting his confidence in the healthcare system.

Different beliefs concerning time conceptions, communication norms, and harmonious relationships also create communication challenges. According to Claramita, Nugraheni, van Dalen \& van der Vleute, (2013), respect for authority is higher in South-East Asia, and thus, patients try to avoid conflicts with physicians. This implies that the participation of patients in the treatment process is insignificant. A study by Burton (2012) among Aboriginals in Guatemala found that direct communication was perceived to be insulting, rude, and careless in the culture of the community. Thus, aboriginal patients are likely to report negative experiences communicating with physicians who do not understand the Aboriginal communication norms.

\subsection{Religious Beliefs}

According to Basu-Zharku (2011), the topic of religion often pops up in all discussions. Religion empowers individuals to connect with their community and to a higher force, bringing about psychological stability. According to Rumun (2014), religion is largely communal, implying that boundaries define it at the cultural and social levels. There are two main ways through which religion influences health. Rumun (2014) further revealed 
that the first way is through regulation of health behavior whereby some religions prescribe certain diets while discouraging others such as smoking. The second way is through social support, whereby some religions define social relations.

Alcorn et al. (2010) found that 58\% of cancer patients are engaged in religious practices to cope with illnesses. Physicians also have their religious beliefs. For instance, some religions forbid abortion, and the practice is considered sinful (Rumun, 2014). Moreover, some religions forbid discussions related to sexuality and family planning. Understanding the religious beliefs of patients is also important in making referrals to spiritual leaders. Physicians and nurses often refer patients to spiritual leaders for spiritual and emotional concerns. Emotional issues include hostility, anxiety, pain, depression, etc. (Johnson, 2010).

\subsection{Discrimination and Stereotyping}

Discrimination based on ethnic and racial backgrounds, and gender, is another factor that can affect patient-physician communication. Two of the studies have demonstrated that physicians discriminate against women and ethnic/racial minorities (Blair et al., 2013; Moskowitz, Stone \& Childs, 2012). According to Blair et al (2013), physicians not only perceive various ethnicities or races and genders differently, but also diagnose and treat them differently. A study by Melton, Graff, Holmes, Brown, Bailey (2014) found that physicians treated African-Americans based on the stereotype of being work-shy, unintelligent, poor, and having an unhealthy diet. Such stereotypes can make physicians overlook important information shared by the patient and consequently, result in poor treatment outcomes.

Mazzocco \& Brunner (2012) have argued that racial/ethnic discrimination is not obvious, but subtle. In addition, Mazzocco and Brunner (2012) have found that individuals unconsciously discriminate against others based on race, and are often willing to correct common racial/ethnic bias. Since discrimination can be unnoticed by other individuals except for the patient, the biases and stereotyping can be unconscious (Blair et al., 2013). Racial or ethnic discrimination can lead to bad feelings, incorrect treatment, and miscommunication between the patient and the physician.

\subsection{Acculturation}

According to Rocque \& Leanza (2015), acculturation involves contact between two cultures, and this process can either positively or negatively affect patient-physician communication. Following acculturation, an individual may integrate both cultures and affiliate with one of the cultures. For instance, a study by Fagerli, Lien, and Wandel (2007) found that patients rated their communication experiences differently based on their levels of integration with the host culture. Another study found that Hispanic immigrants needed to develop positive relationships with the physician before sharing personal information (Julliard, Vivar, Delgado, Cruz, Kabak \& Sabers, 2008). Developing good relationships takes considerable time, and thus, miscommunication is expected in early interactions. According to Rocque \& Leanza,(2015), individuals who are acculturated tend to be knowledgeable regarding the language of the host country, and thus language differences tend to have a lesser impact (Rocque \& Leanza, 2015).

\subsection{Social Factors in Communication}

Social interaction is also another key factor in patient-physician interaction. Most patients from ethnic minority groups value physicians who show interest in the well-being of the family of the patient (Mitchison et al., 2012). Involving family members in the treatment process is a challenge because physicians are often used to communicating directly with the patient rather than with the family of the patient. Some patients consider their illness to be connected to their family and community context, and thus, culture, relations, and values cannot be separated (Mack, Paulk, Viswanath \& Prigerson, 2010).

\subsection{Traumatic Experience}

A traumatic experience is another factor that affects patient-physician communication. Refugees often witness and survive violent and horrific circumstances, which can lead to the development of psychological distress, including depression and post-traumatic stress disorder. An analysis of 181 research papers found that torture and persistent exposure to traumatic events led to the development of post-traumatic stress disorder (Steel et al., 2009). Researchers have found that most physicians feel uncomfortable asking refugees about their experiences, and this becomes a communication barrier (Patricia, O'Dougherty \& Erin, 2012). The refugees also noted that a lack of knowledge regarding mental health symptoms act as a major barrier to seeking care. This demonstrates that understanding the experience of refugees is a key factor in patient-physician communication, and thus, physicians should step up efforts to understand the experience of refugee patients to enhance treatment outcomes. 


\subsection{Communication and Aging}

Interpersonal communication is a very important tool that links people to their environment and helps them in adjusting. When communication problems set in, the situation is disappointing for the older person as well as the caregivers. The elderly person may become upset by the lack of ability to hear or even understand what the people around them say. Furthermore, elderly people may experience difficulties in expressing ideas. In a case where there is a caregiver, it can be frustrating due to obstacles in effective communication. As far as communication is concerned, the difficulties experienced include challenges with speaking and understanding as well as impairment of writing and reading capabilities (Gasiorek, Fowler, \& Giles, 2015).

Communication disorders are common among people of all ages, but complexity is experienced more among the aged ones. There is a significant correlation between the age of the individual and their capability to communicate (Yorkston, Bourgeois \& Baylor, 2010). Disabilities in communication can be explained as a dynamic process that varies with time. In most cases, a person can live long with perfect communication abilities, but experience diminishing abilities to pass and/or receive messages due to age or the onset of health complications such as a stroke (Yorkston, Bourgeois \& Baylor, 2010). The caregivers should handle the problems carefully, especially after diagnosis that offers a base for treatment (Gasiorek, Fowler, \& Giles, 2015).

Some communication disorders are reversible, while others are not. Infections, depression, or medicines can cause temporary and reversible cases of communication and aging. Some medical procedures in healthcare can result in fatigue or confusion where individuals are unable to perceive the environment or communicate clearly. In such cases, the change of medical treatments can eliminate the issues. In other cases, communication problems can be a result of strokes, Parkinson and Alzheimer diseases, and brain tumors. If not treated, the disorder can result in permanent impairments (Gerlach, 2012). Many strategies are used by professional nursing practitioners to overcome the specific problem concerning the primary cause. In most cases, elderly people suffer from being ignored and isolated due to their disability to communicate properly. Instead of isolating the aging generation, steps to diagnose the cause of the problem should be implemented first.

In a new cultural environment, caregivers may face communication challenges due to unfamiliarity with the language and the culture. Communication is altered mainly due to the language barrier where the patients cannot express themselves effectively to the nurses. Aging factors among patients can be a huge obstacle to the healthcare delivery process. It calls for a native nursing practitioner or an interpreter who communicates the patient's feelings to the nurse (Blignault, 2008). However, the nurse should learn the language and culture of the people in order to offer health care services with no mistakes.

\subsection{Generation Cross Culture}

The concept of cross-culture is more linked to communication differences and strategies. Different cultural groups have various ways of communication that have become their norms. A nursing practitioner who works in a new cultural environment must learn how to do things the way the community wants. In communication, some aspects that differ include pacing, pausing, when to talk, intonation, the art of listening, coherence, cohesion, and what to say during conversations. Individuals must follow the style of communication keenly in order to maintain their relationships with the members of the community (Vieregge \& Quick, 2011).

Some practices may be new to professional physicians, such as how to talk to elderly patients and what to say. Cross-cultural awareness is very important for individuals who deal directly with members of the community. It is crucial to have cross-cultural skills in order to survive in various working environments comfortably (Vieregge \& Quick, 2011). In most cases, culture shock is normal when the culture of the new environment has different practices from the victim's home culture. However, learning and appreciating culture is a solution.

\subsection{Adapting to a New Culture}

Generally, adapting to a new culture may lead to cultural shock. It is because a victim may find adapting difficult if everything is unfamiliar such as language, food, values, fashion, weather, and customs. The degree of shock depends on the flexibility, tolerance for ambiguity, and the difference between the new culture and home culture. Individuals can adapt quickly if the conditions are too different from their native cultures. However, a different culture can be stressful (Hoppner, Griffith, \& White, 2015). Symptoms include homesickness, frustration, fatigue, and even depression.

To adapt to a new culture requires an open mind so that individuals are ready for changes. Also, individuals in a new culture should not isolate themselves from the members of the community. Culture is learned from native members and/or people who are used to the environment. Furthermore, it is very important to ask questions to people for clarification of the practices or language used. Another important strategy is to allow oneself to make 
mistakes rather than feeling frustrated (Hoppner, Griffith, \& White, 2015). Finally, individuals who are new to a culture should learn how to work with the culture instead of fighting it. Supporting the culture helps to learn more and get better results.

\section{Discussion}

Language differences can be an important barrier to intercultural communication resulting in frustration in different situations, leading to misunderstandings, and further making it impossible for physicians to achieve shared decision-making (Morgeson, 2010). During patient-physician interaction, physicians need specific skills to facilitate communication. Although physicians are not expected to know multiple languages in a multicultural setting, knowing a few words can facilitate communication and help build a good relationship with the patient (Brugge, Edgar, George, Heung, \& Laws, 2009). When communication difficulties arose, patients avoided sharing their views due to the fear of being misunderstood, whereas clinicians also avoided seeking clarification. Language barriers affect not only patient-physician interactions but also the ability of a patient to understand health information (Andrews, 2008). Based on these findings, it is clear that language differences affect the effectiveness of patient-physician communication (Mounts, 2006). When a patient believes that there is alignment between their preferences and those of physicians, greater adherence to medication is likely to be realized.

Non-verbal behaviours vary across cultures, and thus physicians or patients can misinterpret them, contributing to communication challenges. For instance, every patient responds differently when subjected to pain. One culture may have self-control, while another culture may moan when a pain stimulus is applied. The way a health professional interprets the non-verbal behaviors of patients' influences the type of pain management therapies recommended. Such perspective differences can negatively affect treatment decisions and consequently affect treatment outcomes even when appropriate therapy is applied. The biomedical model influences the beliefs and perceptions of physicians, patient values and beliefs are influenced by behavioral and social factors, which tend to be culturally specific (Molfenter \& Brown, 2014). Despite the desire of some patients to be acknowledged as authorities of their illness, most of them remain passive due to respect for the physicians (Rose \& Harris, 2015). Communication norms can also threaten patient-physician communication.

In patient-physician communication, faith-based preferences may come up, and these preferences may crash with the physician's views. The ability of religion to empower individuals can be used in healthcare to promote healthy living behaviors or to encourage those struggling with illness. Empowerment often occurs through the consciousness of religious principles such as social networks, social and economic support, shared identity, meaningful roles, and conflict protection. Thus, differences in religious beliefs between the physician and the patient can have an impact on physician-patient communication. Discrimination based on race or ethnic backgrounds can also make it difficult for patients to seek care. For instance, a study of in Guatemala found that patients from the aboriginal group experienced severe discrimination such as insults, abuse, or being mocked, this consequently discouraged them from freely accessing medical facilities and sharing personal information (Dahm, 2012).

Medical assumptions by the physician can also affect patient-physician communication. In their practice, physicians can develop assumptions and prejudice for a given culture. Most of these experiences are negative; they can make the physicians interact negatively with patients who are from the same culture as previous patients (Ameresekere et al., 2011). For instance, some physicians generalize their thoughts about an entire ethical group, which make ethical group feel treated unequally and discriminated (Gerlach, Abholz, Koc, Yilmaz, \& Becker, 2012). Recognizing such experiences and taking actions to prevent them from interfering with physician-patient interaction is a core skill of physicians.

The degree of integration with the host culture has a significant effect on communication perceptions. Particularly, individuals who were fully integrated appreciated taking responsibility for their health, inquiry regarding psychosocial information, and social talk (Fengler, 2012). On the contrary, less integrated individuals did not appreciate physician inquiry about their personal life or when their opinion was sought (Goodall, 2002). Miscommunication in this context occurs due to a misunderstanding between the physician and patient regarding the role of family members in the treatment process (Goodman, 2009). Thus, understanding the habits and expectations of the patients and their families is core strength for physicians, and these skills can enable them to build good relationships and handle emotions of the patients as well as their families (Kouzes, 2007). When the physician understands the context of the patients, he/she can adopt behaviors that can meet patient expectations (Mathieu, 2008). This can consequently improve communication outcomes. Due to the extreme stress associated with traumatic events, refugees may also develop problems associated with domestic violence and substance use. In most cases, the initial medical visit refugees make present an opportunity to detect physical and psychological 
symptoms associated with traumatic experiences. Thus, physicians need to identify trauma histories through mental assessment. In addition, the aging disability is linked to people who have lifelong or early onset of communication problems due to cerebral palsy and age. Regardless of the trajectory, the concern of having communication problems grows with age and has implications for healthcare providers. People affected by aging communication problems must seek treatments before it interferes with their abilities as well as relationships.

\subsection{Recommendations}

Based on the findings, the study would like to present two core agendas in a patient-centered approach. First, the physician focuses on explaining an illness in medical terms. Second, the patient focuses on understanding the information provided (King \& Hoppe, 2013). In this relationship, the physician tries to resolve any issues that may arise in the exchange by employing negotiation and dialogue as communication barriers were found to be most devastating in the patient-physician relationship. The figure below presents the other measures which can be implemented at a policy level for overcoming the cultural barriers which impede the effective health management of the patients.

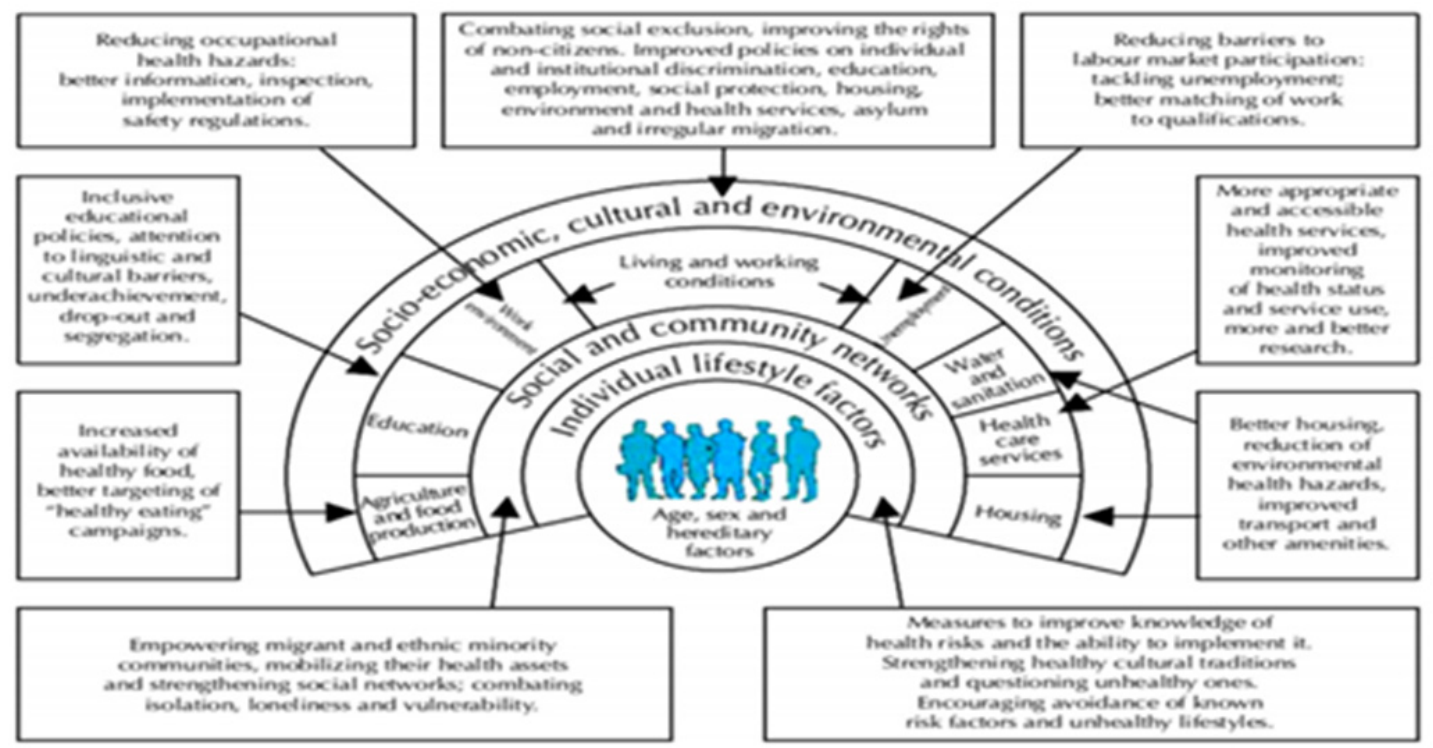

Figure 1. Policy measures for Health Management of Refugees (Matlin et al., 2018).

For an institution working with older refugees aged above 55 years, various measures have to be adapted to enhance patient-physician communication. Older refugees have a history with their culture, and changing their health beliefs is not easy (Collins, 2007). Thus, a physician should seek to understand the health beliefs of such patients before engaging in a medical conversation (King \& Hoppe, 2013). The physician should also elicit personal and religious beliefs to build a positive relationship with older patients. Understanding such beliefs is particularly significant when deciding the approach to use in discussing the end-of-life issues (Edger, 2012). Moreover, older refugees tend to understand only their native language, and hence, it is necessary to acquire the services of an interpreter (Schider, 2017). The physicians should also involve the family of the patients for some illnesses associated with older people and their required support and care (Smith et al., 2013).

Further recommendations for improving the refugee health management at a large scale include responding to the language and cultural barriers in the region. For this, Clark et al. (2014) has suggested that the community health worker model (CHW) should be adopted for resolving the language issues and cultural barriers for accessing the health care system. It is because CHW considers the social networks and community identity among communities, peer to peer teaching, and using interventions focused on refugees through health education.

Also, a refugee must be exposed to health education intervention, which should be paired with English lessons, integrating specific vocabulary focused on physical, mental, and social health (Frost, 2016). Similarly, the partnership must be established with resettlement agencies for supporting health education intervention. This should begin with the staff members as well as directors of the resettlement agencies for improving models for health promotion planning (Eldredge et al., 2016). Also, an ecological framework for social work can be formulated for health promotion among refugee communities. 


\section{Conclusion}

This study has concluded that various cultural factors affect patient-physician communication. Language difference is considered as one of the most important barriers to patient-physician communication. It was also observed that physicians may find it difficult in assessing the extent of the symptoms or even describing diagnosis and treatment options to the patient. In addition to language differences, different health beliefs can affect patient-physician communication. Individuals from different cultures have different health beliefs, which can influence the way conversations are carried out. Moreover, time concept, communication norms, and harmonious relationships also create communication challenges complicated.

Apart from language differences and health beliefs, religious beliefs also affect patient-physician communication. Stereotyping and discrimination also affect the patient-physician relationship. Stereotyping involves having a generalized perception regarding a given culture, while discrimination is based on the ethnic or racial background of the patient. Acculturation also influences physician-patient communication. Individuals who are fully acculturated are likely to experience better and effective communication as compared to those who are sparingly acculturated. Finally, social practices, such as the involvement of families in the treatment process and experiences, affect patient-physician communication. Addressing these potential barriers can enhance the quality of communication between the physician and patients and consequently improve health outcomes.

\section{Availability of Data and Materials}

The datasets used and analysed during the current study are available from the corresponding author on reasonable request.

\section{Funding}

This research is not funded by any resource.

\section{Acknowledgements}

The author is very thankful to all the associated personnel in any reference that contributed in/for the purpose of this research.

\section{Competing Interests Statement}

The author declares no competing interest.

\section{References}

Abubakar, I., \& Zumla, A. (2018). Universal health coverage for refugees and migrants in the twenty-first century. https://doi.org/10.1186/s12916-018-1208-2

Alcorn, S. R. (2010). "If God wanted me yesterday, I wouldn't be here today": Religious and spiritual themes in patients' experiences of advanced cancer. Journal of Palliative Medicine, 5, 581-588. https://doi.org/10.1089/jpm.2009.0343

Almutairi, A. (2012). A multicultural nursing workforce and cultural perspectives in Saudi Arabia: An overview. The Health, 3, 71-74.

Almutairi, K. M. (2015). Culture and language differences as a barrier to the provision of quality care by the health workforce in Saudi Arabia. Saudi medical journal, 36(4), 425. https://doi.org/10.15537/smj.2015.4.10133

Ameresekere, M. B. (2011). Somali immigrant women's perceptions of cesarean delivery and patient-provider communication surrounding female circumcision and childbirth in the USA. Int J Gynaecol Obstet, 115, 227-230. https://doi.org/10.1016/j.ijgo.2011.07.019

Andrews, M. (2008). Transcultural concepts in nursing care. Philadelphia: Wolters Kluwer Health/Lippincott Williams \& Wilkins.

Beardsmore, E., \& McSherry, R. (2017). Healthcare workers' perceptions of organisational culture and the impact on the delivery of compassionate quality care. Journal of Research in Nursing, 22(1-2), 42-56. https://doi.org/10.1177/1744987116685594

Bempong, N. E., Sheath, D., Seybold, J., Flahault, A., Depoux, A., \& Saso, L. (2019). Critical reflections, challenges and solutions for migrant and refugee health: 2nd M8 Alliance Expert Meeting. https://doi.org/10.1186/s40985-019-0113-3

Blair, I. V. (2013). Clinicians' implicit ethnic/racial bias and perceptions of care among black and Latino patients. Annals of Family Medicine, 11(1), 43-52. https://doi.org/10.1370/afm.1442

Blignault, I. P. (2008). A qualitative study of barriers to mental health services utilisation among migrants from 
mainland China in south-east Sydney. Int $J$ Soc Psychiatry, 54(2), 180-190. https://doi.org/10.1177/0020764007085872

Brugge, D. E. (2009). Beyond literacy and numeracy in patient provider communication: focus groups suggest roles for empower- ment, provider attitude and language. BMC Public Health, 354. https://doi.org/10.1186/1471-2458-9-354

Burton, L. (2012). Defacement: Indigenous Patients' Experiences in Baja Verapaz, Guatemala. How J Comm, 23(2), 119-35. https://doi.org/10.1080/10646175.2012.667723

Campbell, R. M., Klei, A. G., Hodges, B. D., Fisman, D., \& Kitto, S. (2014). A comparison of health access between permanent residents, undocumented immigrants and refugee claimants in Toronto, Canada. Journal of Immigrant and Minority Health, 16(1), 165-176. https://doi.org/10.1007/s10903-012-9740-1

Choudhry, F. R., Mani, V., Ming, L. C., \& Khan, T. M. (2016). Beliefs and perception about mental health issues: a meta-synthesis. Neuropsychiatric disease and treatment, 12, 2807. https://doi.org/10.2147/ndt.s111543

Claramita, M. N. (2013). Doctor-patient communication in Southeast Asia: a different culture? Adv Health Sci Educ Theory Pract, 18(1), 15-31. https://doi.org/10.1007/s10459-012-9352-5

Clark, A., Gilbert, A., Rao, D., \& Kerr, L. (2014). ‘Excuse me; do any of you ladies speak English?'Perspectives of refugee women living in South Australia: barriers to accessing primary health care and achieving the Quality Use of Medicines. Australian Journal of Primary Health, 20(1), 92-97. https://doi.org/10.1071/py11118

Clarkson Freeman, P. A., Penney, D. S., Bettmann, J. E., \& Lecy, N. (2013). The intersection of health beliefs and religion among Somali refugees: A qualitative study. Journal of Religion \& Spirituality in Social Work: Social Thought, 32(1), 1-13. https://doi.org/10.1080/15426432.2013.749141

Collins, H (2007). Rethinking Expertise. Chicago: University of Chicago Press.

Corby, M. R. (2010). Developing Health Communication with Displaced Populations: An Exploration of Cultural Barriers to Health Care Experienced by Southeast Asian Refugees. The Elon Journal of Undergraduate Research in Communications, 1(2), 44-50.

Cross, W. M. (2010). Extending boundaries: clinical communication with culturally and linguistically diverse mental health clients and carers. Int $J$ Ment Health Nurs, 19(4), 268-277. https://doi.org/10.1111/j.1447-0349.2010.00667.x

Dahm, M. (2012). Tales of Time, Terms, and Patient Information-Seeking Behavior-An Exploratory Qualitative Study. Health Commun, 27(7), 682-689. https://doi.org/10.1080/10410236.2011.629411

Degni, F. S.-J. (2012). Communication and cultural issues in providing reproductive health care to immigrant women: health care providers' experiences in meeting the needs of [corrected] Somali women living in Finland. J Immigration Minor Health, 14, 330-343. https://doi.org/10.1007/s10903-011-9465-6

Diamond, L. T. (2012). The use of Spanish language skills by physicians and nurses: policy implications for teaching and testing. J Gen Intern Med, 2(27), 117-123. https://doi.org/10.1007/s11606-011-1779-5

Edger, C. (2012). Effective Multi-unit Leadership: Local Leadership in Multi-site Situations. Gower Publishing, Ltd. https://doi.org/10.4324/9781315578934

Eldredge, L. K. B., Markham, C. M., Ruiter, R. A., Fernández, M. E., Kok, G., \& Parcel, G. S. (2016). Planning health promotion programs: an intervention mapping approach. John Wiley \& Sons.

Ellis, B. H., Lankau, E. W., Ao, T., Benson, M. A., Miller, A. B., Shetty, S., ... \& Cochran, J. (2015). Understanding Bhutanese refugee suicide through the interpersonal-psychological theory of suicidal behavior. American journal of orthopsychiatry, 85(1), 43.

Fagerli, R. L. (2007). Health worker style and trustworthiness as perceived by Pakistani-born persons with type 2 diabetes in Oslo, Norway. Health, 11(1), 109-29. https://doi.org/10.1177/1363459307070810

Fengler, W. (2012). Kenya's education dividend. Retrieved 2 18, 2016, from http://blogs.worldbank.org//africacan/kenya-s-education-dividend

Fowler, M. (2012). Religion, religious ethics, and nursing. New York: Springer Pub. Co.

Frost, E. (2016). Refugee health education: Evaluating a community-based approach to empowering refugee women in Houston, Texas (Doctoral dissertation, The University of Texas School of Public Health).

Frost, E. L., Markham, C., \& Springer, A. (2018). Refugee health education: Evaluating a community-based approach to empowering refugee women in Houston, Texas. Advances in Social Work, 18(3), 949-964. 
https://doi.org/10.18060/21622

Garrett, P. D. (2008). What do non-englishspeaking patients value in acute care? Cultural competency from the patient's perspective: A qualitative study. Ethnicity and Health, 13, 479-496. https://doi.org/10.1080/13557850802035236

Gasiorek, J., Fowler, C., \& Giles, H. (2015). What Does Successful Aging Sound Like? Profiling Communication About Aging. Human Communication Research, 577-602. https://doi.org/10.1111/hcre.12060

Ge, G. B. (2009). Considering culture in physician-patient communication during colorectal cancer screening. Qual Health Res, 19, 778-89. https://doi.org/10.1177/1049732309335269

Gerlach, H. A. (2012). As a migrant $\mathrm{i}$ wish not to be treated differently Focus-groups on the experience of patients with migration background from Turkey. Z Allg med, 88, 77-85.

Gerteis, M. E. (1993). Through the patient's eyes: Understanding and promoting patient centered care. San Francisco: Jossey Bass.

Goodall, A. H. (2012). A theory of expert leadership.

Goodman, P. S. (2009). Self-Managing Teams. In J. a. M.A.Hogg, Encyclopedia of Group Processes and Intergroup Relations. Thousand Oaks, CA: Sage. https://doi.org/10.4135/9781412972017.n226

Goodridge, E. (2002). Meeting the health needs of refugees and immigrants. Journal of the American Academy of Physician Assistants, 15(1), 20-2, 25-6.

Groen, S. P., Richters, A., Laban, C. J., \& Devillé, W. L. (2018). Cultural identity among Afghan and Iraqi traumatized refugees: Towards a conceptual framework for mental health care professionals. Culture, Medicine, and Psychiatry, 42(1), 69-91. https://doi.org/10.1007/s11013-016-9514-7

Hagaman, A. K., Sivilli, T. I., Ao, T., Blanton, C., Ellis, H., Cardozo, B. L., \& Shetty, S. (2016). An investigation into suicides among Bhutanese refugees resettled in the United States between 2008 and 2011. Journal of immigrant and minority health, 18(4), 819-827.

Hashim, M. J. (2017). Patient-centered communication: basic skills. American family physician, 95(1), 29-34.

Hoppner, J. J., Griffith, D. A., \& White, R. C. (2015). Reciprocity in Relationship Marketing: A Cross-Cultural Examination of the Effects of Equivalence and Immediacy on Relationship Quality and Satisfaction with Performance. Journal of International Marketing, 64-83. https://doi.org/10.1509/1069-0031x-23.4.64

Hughes, C. R., van Heugten, K., \& Keeling, S. (2015). Cultural meaning-making in the journey from diagnosis to end of life. Australian Social Work, 68(2), 169-183. https://doi.org/10.1080/0312407x.2014.939668

International Institute of Akron. (2014). Social Services. Retrieved from iiakron.org: http://iiakron.org/refugee-resettlement/social-services/

Julliard, K. V. (2008). What Latina patients don't tell their doctors: a qualitative study. Ann Fam Med, 6, $543-549$.

King, A., \& Hoppe, R. B. (2013). "Best practice” for patient-centered communication: a narrative review. Journal of graduate medical education, 5(3), 385-393. http://dx.doi.org/10.4300/JGME-D-13-00072.1

Kira, I. A., Amer, M. M., \& Wrobel, N. H. (2014). Arab refugees: Trauma, resilience, and recovery. In Biopsychosocial Perspectives on Arab Americans (pp. 175-195). Springer, Boston, MA.

Kouzes, J. (2007). The Five Practices of Exemplary Leadership” from The Leadership Challenge. Jossey-Bass.

Kumar, G. S., Varma, S., Saenger, M. S., Burleson, M., Kohrt, B. A., \& Cantey, P. (2014). Noninfectious disease among the Bhutanese refugee population at a United States urban clinic. Journal of immigrant and minority health, 16(5), 922-925.

Kumar, S., \& Preetha, G. S. (2012). Health promotion: an effective tool for global health. Indian journal of community medicine: official publication of Indian Association of Preventive \& Social Medicine, $37(1), 5$.

Mack, J. P. (2010). Racial disparities in the outcomes of communication on medical care received near death. Arch Intern Med, 170, 1533-1540.

Mangrio, E., \& Forss, K. S. (2017). Refugees' experiences of healthcare in the host country: a scoping review. BMC health services research, $17(1), 814$.

Mathieu, J. E. (2008). Team effectiveness 1997-2007: A review of recent advancements and a glimpse into the future. Journal of Management, 34, 410-476.

Matlin, S.A., Depoux, A., Schütte, S. et al. (2018). Migrants' and refugees' health: towards an agenda of solutions. 
Public Health Reviews 39, 27. https://doi.org/10.1186/s40985-018-0104-9

Mazzocco, P. J. (2012). An experimental investigation of possible memory biases affecting support for racial health care policy. American Journal of Public Health, 102(5), 1002-1005.

Melton, C. G. (2014). Health literacy and asthma management among African-American adults: an interpretative phenomenological analysis. J Asthma, 51(7), 703-713.

Meuter, R. F., Gallois, C., Segalowitz, N. S., Ryder, A. G., \& Hocking, J. (2015). Overcoming language barriers in healthcare: a protocol for investigating safe and effective communication when patients or clinicians use a second language. BMC health services research, 15(1), 371.

Mitchison D., B. P. (2012). Prognostic communication preferences of migrant patients and their relatives. Psy-chooncology, 21, 496-504.

Molfenter, T. \& Brown, R. L. (2014). Effects of Physician Communication and Family Hardiness on Patient Medication Regimen Beliefs and Adherence. Gen Med, 2, 136. https://doi.org/10.4172/2327-5146.1000136

Morgeson, P. F. (2010). Leadership in Teams: A Functional Approach to Understanding Leadership Structures and Processes. Journal of Management, 36(1), 5-39.

Moskowitz, G. B. (2012). Implicit stereotyping and medical decisions: Unconscious stereotype activation in practitioners' thoughts about African Americans. American Journal of Public Health, 102(5), 996-1001.

Mounts, Y. K. (2006). Stepping Out from a Technical Job and Leaping Into Management: A Dissertation. iUniverse.

Napier, D., Depledge, M. H., Knipper, M., Lovell, R., Ponarin, E., Sanabria, E., \& Thomas, F. (2017). Culture matters: using a cultural contexts of health approach to enhance policy-making. World Health Organization Regional Office for Europe.

Neo, F. (2011). Working toward the best doctor-patient communication. Singapore Med J, 52(10), 720-725.

Neumann, K., Gifford, S. M., Lems, A., \& Scherr, S. (2014). Refugee settlement in Australia: policy, scholarship and the production of knowledge, 1952-2013. Journal of Intercultural Studies, 35(1), 1-17.

Nguyen, G. B. (2008). Cancer and communication in the health care setting: experiences of older Vietnamese immigrants, a qualitative study. $J$ Gen Intern Med, 23(1), 45-50.

Nyangau, J. Z. (2014). Higher Education as an Instrument of Economic Growth in Kenya. Forum for International Research in Education, 1(1), 7-25.

Piacentini, T., O’Donnell, C., Phipps, A., Jackson, I., \& Stack, N. (2019). Moving beyond the 'language problem': developing an understanding of the intersections of health, language and immigration status in interpreter-mediated health encounters. Language and Intercultural Communication, 19(3), 256-271.

Professional Managers Australia. (2014). Transitioning to Management. Retrieved from www.professionalsaustralia.org.au http://www.professionalsaustralia.org.au/managers/support/career-progression/moving-management/manag ement-guides/transitioning-management/

Purnell, L. (2013). Transcultural health care: A culturally competent approach. Philadelphia: F.A. Davis.

Rees, D., \&. Porter, C. (2015). Skills of Management and Leadership: Managing People in Organisations. Palgrave Macmillan.

Rocque, R., \& Leanza, Y. (2015). A systematic review of patients' experiences in communicating with primary care physicians: intercultural encounters and a balance between vulnerability and integrity. PloS one, 10(10), e0139577.

Rose, V. (2015). Experiences of self-management support from GPs among Australian ethnically diverse diabetes patients: a qualitative study. Psychol Health Med, 20(1), 114-20.

Rumun, A. J. (2014). Influence of Religious Beliefs on Healthcare Practice. International Journal of Education and Research, 2(4), 37-48.

Sandhu, S. B. (2013). Experiences with treating immigrants: a qualitative study in mental health services across 16 European countries. Soc Psychiatry Psychiatr Epidemiol, 48(1), 105-116.

Santosh, K. C. (2014). Communication in cancer care: psycho-social, interactional, and cultural issues. A general overview and the example of India. Front Psychol, 5, 1332.

Schider, S. (2017). Interpreters as Agents in the Refugee Crisis (Doctoral dissertation). 
Schultze, M. L. (2018). Bhutanese Refugees Are Finding Their Place in Ohio. Retrieved from https://www.huffpost.com/entry/akron-ohio-bhutanese-refugees_n_59ca88cfe4b0cdc7733353640

Schyve, P. (2007). Language differences as a barrier to quality and safety in health care: the Joint Commission perspective. J Gen Intern Med, 22(2), 360-361.

Shannon, P. O. (2012). Refugees' perspectives on barriers to communication about trauma histories in primary care. Ment Health Fam Med, 9(1), 47-56.

Smith, M., Saunders, R., Stuckhardt, L., \& McGinnis, J. M. (2013). Engaging Patients, Families, and Communities. In Best Care at Lower Cost: The Path to Continuously Learning Health Care in America. National Academies Press (US).

Song, L. H. (2011). Patient-healthcare provider communication: perspectives of African American cancer patients. Health Psychol, 31(5), 539-547.

Spaaij, R., Broerse, J., Oxford, S., Luguetti, C., McLachlan, F., McDonald, B., ... \& Pankowiak, A. (2019). Sport, refugees, and forced migration: A critical review of the literature. Frontiers in Sports and Active Living, 1, 47.

Street, R. M. (2009). How does communication heal? Pathways linking clinician-patient communication to health outcomes. Patient Educ Couns, 74, 295-301.

Sweileh, W. M. (2018). Global research output in the health of international Arab migrants (1988-2017). BMC public health, 18(1), 755.

Tay, A. K., Islam, R., Riley, A., Welton-Mitchell, C., Duchesne, B., Waters, V., ... \& Ventevogel, P. (2018). Culture, Context and Mental Health of Rohingya Refugees: A Review for Staff in Mental Health and Psychosocial Support Programmes for Rohingya Refugees.

UNHCR. (2018). Global Trends Forced Displacement in 2018. Retrieved from worldreliefakron.org: https://www.unhcr.org/5d08d7ee7.pdf

Vieregge, M., \& Quick, S. (2011). Cross-cultural negotiations revisitedAre Asian generations X and Y members negotiating like their elders? Cross Cultural Management, 313-326.

Von Fragstein, M., Silverman, J., Cushing, A., Quilligan, S., Salisbury, H., Wiskin, C., \& UK Council for Clinical Communication Skills Teaching in Undergraduate Medical Education. (2008). UK consensus statement on the content of communication curricula in undergraduate medical education. Medical education, 42(11), 1100-1107.

Von, F. S. (2008). UK consensus statement on the content of communication curricula in under-graduate medical education. Med Educ, 42, 1100-1107.

Wolz, M. M. (2015). Language barriers: challenges to quality healthcare. International journal of dermatology, 54(2), 248-250.

Wynia, M. (2010). Health literacy and communication quality in health care organizations. $J$ Health Commun, 15(2), 102-115. https://doi.org/10.1080/10810730.2010.499981

Yilmaz, M., Toksoy, S., Direk, Z. D., Bezirgan, S., \& Boylu, M. (2017). Cultural sensitivity among clinical nurses: A descriptive study. Journal of Nursing Scholarship, 49(2), 153-161. https://doi.org/10.1111/jnu.12276

Yorkston, K. M., Bourgeois, M. S., \& Baylor, C. R. (2010). Communication and aging. Physical Medicine and Rehabilitation Clinics, 21(2), 309-319.

Zhao, X. (1-17). Cancer information disparities between U.S. - and foreign-born populations. Journal of Health Communication, 15, 2010. https://doi.org/10.1080/10810730.2010.522688

\section{Copyrights}

Copyright for this article is retained by the author(s), with first publication rights granted to the journal.

This is an open-access article distributed under the terms and conditions of the Creative Commons Attribution license (http://creativecommons.org/licenses/by/4.0/). 